\title{
NUMERICAL AND EXPERIMENTAL INVESTIGATION OF SLOT-BLOWN AIR OVER A CYLINDER
}

\section{W. Runge ${ }^{1}$, F. Buysschaert ${ }^{1}$, J. Hayez ${ }^{1}$, F. Carlier ${ }^{2}$, H. Antoine ${ }^{3}$, P. Hendrick ${ }^{1}$, G. Dimitriadis ${ }^{2}$, and G. Degrez ${ }^{1}$}

${ }^{1}$ Université Libre de Bruxelles, Faculté des Sciences Appliquées Aero-Thermo-Mechanics Laboratory CP165/43, 50 F. D. Roosevelt Avenue, Brussels B-1050, Belgium ${ }^{2}$ Université de Liège, Département d'Aérospatiale et Mécanique BAT: B52/3, 1 Chemin des Chevreuils, 4000 Liège 1, Belgium

${ }^{3}$ Sagita

37 Avenue de l'Indépendance, Wandre 4020, Belgium

\begin{abstract}
The paper investigates the concept of directional control of helicopters without tail rotor by means of the Coandă effect. Slot-blowing around a cylinder in a steady flow is modeled computationally, using the unsteady $k-\omega$ shear stress transport (SST) solver in NUMECA, as well as experimentally in the wind tunnel of the Université de Liège. While the concept, in general, is promising, it is shown that there are some potential problems, including pitch-yaw coupling and some unsteady flow conditions. These problems exist under various circumstances and are due, at least, in part, due to the complicated flow-field that governs this problem, even in two dimensions.
\end{abstract}

\section{INTRODUCTION}

Over the past several decades, the basic concept of a helicopter has changed very little. Some experts believe that conventional helicopter design is approaching the boundaries of its performance [1]. As manufacturers investigate new concepts, such as the performance-oriented Sikorsky X2 demonstrator [2], new possibilities arise for novel helicopters developed from a clean slate. A new helicopter without tail rotor is under development by Sagita, a Belgian aircraft manufacturer. Such helicopters typically use the Coandă effect to counter rotor torque and/or control the yaw at the low air speeds. This paper constitutes a preliminary investigation of this control concept.

This is an Open Access article distributed under the terms of the Creative Commons Attribution License 4.0, which permits unrestricted use, distribution, and reproduction in any medium, provided the original work is properly cited. 
The Coandă effect describes the tendency of a tangentially-blown fluid jet to adhere to a curved or angled surface [3] as the result of a transverse pressure distribution which pushes the jet towards the wall, deflecting its path [4].

This phenomenon has been studied since the early 1900s. Some of the bestknown aeronautical applications of the Coandă effect are in the tail boom of the NOTAR (NO TAil Rotor) helicopter system [5] for antitorque production and in circulation control over airfoils for high lift systems $[6,7]$. In these applications, a pressure source creates a linear jet through one or more slots, blown tangentially to the adjacent surface. This slot-blown air creates a large area of attached flow, resulting in some desirable force on the body, such as increased lift.

\subsection{Aircraft Design Concept}

Sagita's helicopter design is called the Rotor Driven by Embedded Turbine, or Rotor à Entraînment Direct par Turbine (REDT). This proposed concept has a similar external architecture to that of a conventional helicopter, with a fuselage suspended from a main rotor, and a tail boom for yaw control (Fig. 1). However, the drive mechanism for the main rotors and the yaw control system are quite different.

The vehicle, first proposed by Hubert Antoine [8], uses a turbine to drive the coaxial main rotors. The yaw control system is based on slot-blowing, somewhat similar to the system used in the NOTAR helicopter concept [5].

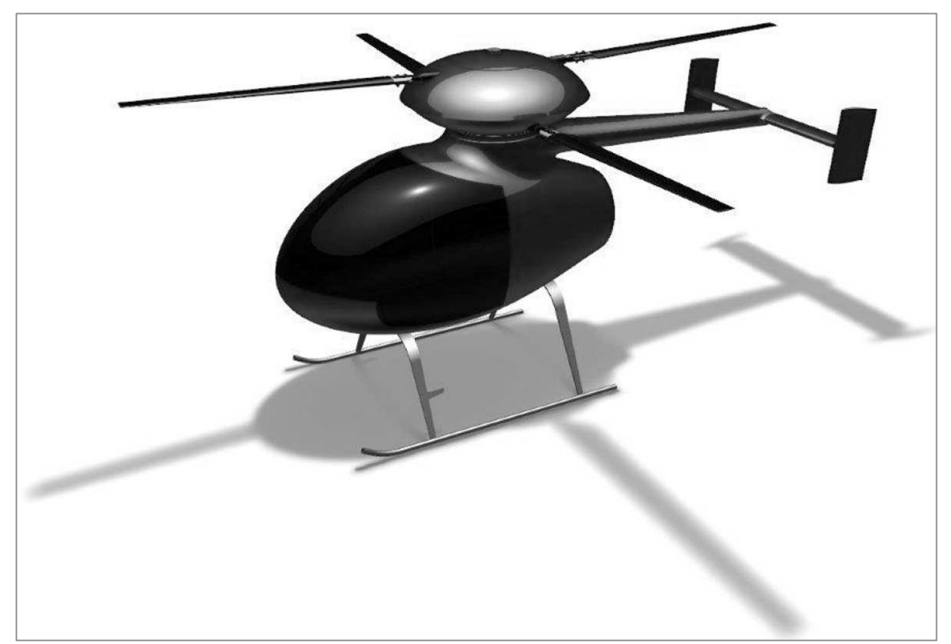

Figure 1 The REDT helicopter concept 


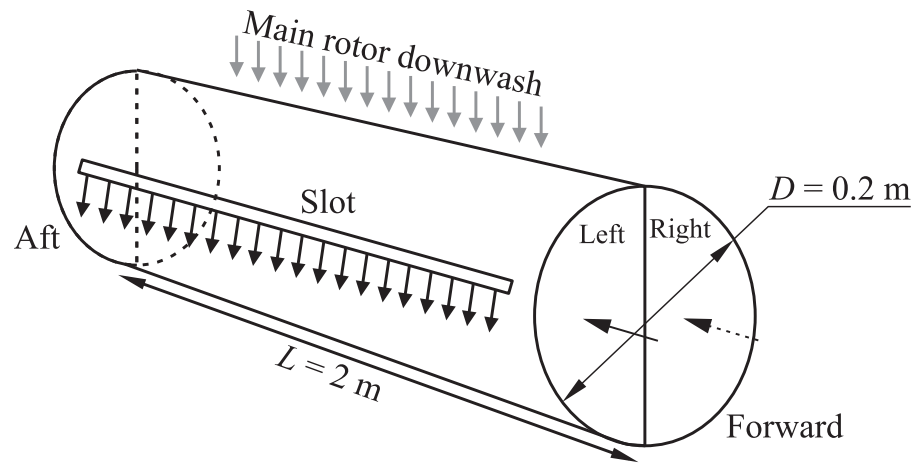

Figure 2 Directional control of the REDT helicopter using Coandă-effect circulation around the tail boom

Typically, in coaxial helicopters, contrarotating main rotors are driven by a gearbox, which allows a torque imbalance between the rotors to be used for yaw control. However, in the case of the REDT, the embedded turbine drives the rotors directly and because there is no mechanical link with the fuselage except via the bearings, directional control has to be achieved via an independent system. Sagita proposes to use slot-blown air from the same pressure source as that which drives the rotor. The main appeal is mechanical simplicity and the resulting potential for improved safety and reduced cost [1].

The current proposed design uses a single slot on either side of the tail boom. Air is blown out from one side or the other depending on the direction of desired yawing moment (Fig. 2).

The two halves of the boom are separated by a partition. Pressurized air is provided to either compartment depending on the pilot's pedal inputs. The tangentially-blown air adheres to the outside of the cylindrical tail boom, creating a circulation which results in the side force on the cylinder (and yawing moment on the aircraft body) that is required by the pilot (Figs. 3 and 4).

Unlike a conventional tail rotor, this system has the potential to create a side force on the tail boom in either direction. Moreover, some mechanical simplicity is gained because the only moving parts of this system are the doors that control which half of the boom receives pressurized air.

The study undertaken here is based on the characteristics of a test vehicle, which has a tail boom that is $0.2 \mathrm{~m}$ in diameter. The tail boom is $2 \mathrm{~m}$ long and has slots that are $1.1 \mathrm{~m}$ long, located on the horizon on either side of the boom. The slot has a gap of $1 \mathrm{~mm}$ from the tail boom surface. The aircraft developers hope to create a pressure ratio in the tail boom of 1.05 to 1.50 compared to atmospheric pressure. 


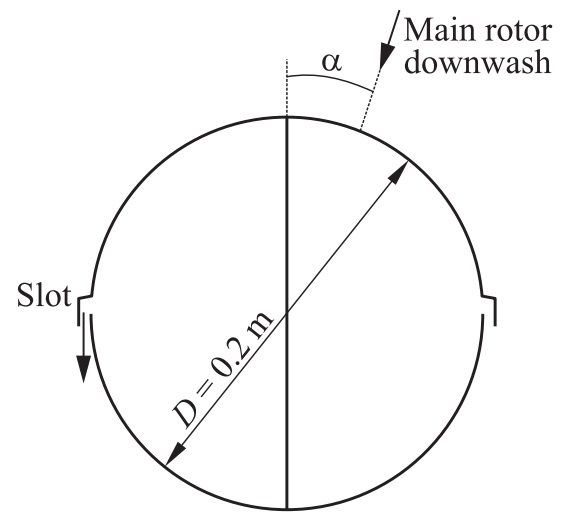

Figure 3 The REDT tail boom; twodimensional view

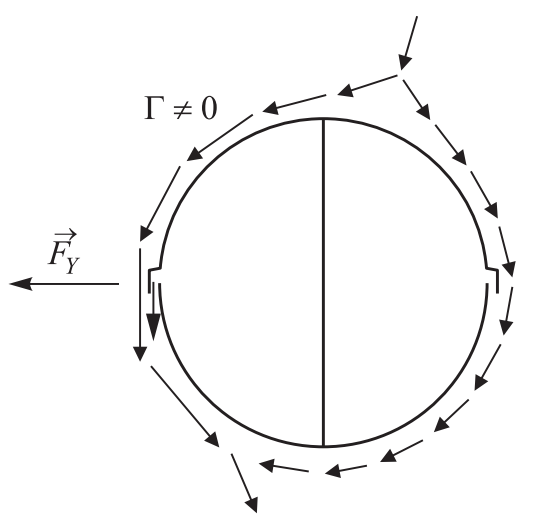

Figure 4 Concept of force generation

\subsection{Experimental Method}

The experiments were performed in the subsonic, closed-loop wind tunnel of the Université de Liège. The model was installed in the aeronautic test section of the wind tunnel (TS1), whose dimensions are $2 \times 1.5 \times 5 \mathrm{~m}$ (width $\times$ height $\times$ length) (Figs. 5 and 6).

The model is a circular cylinder with a diameter of $0.2 \mathrm{~m}$ and a length of $1.1 \mathrm{~m}$. In the interest of simplicity, only one slot was included on the experimental

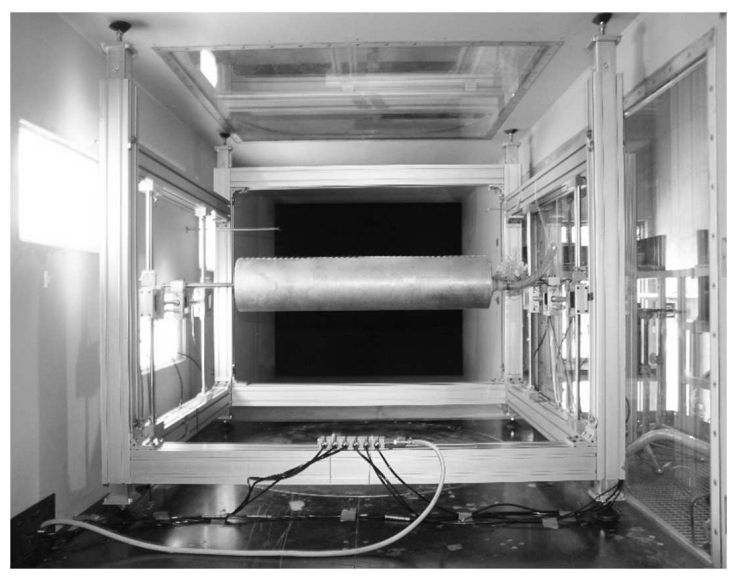

Figure 5 Experimental model in the aeronautic test section

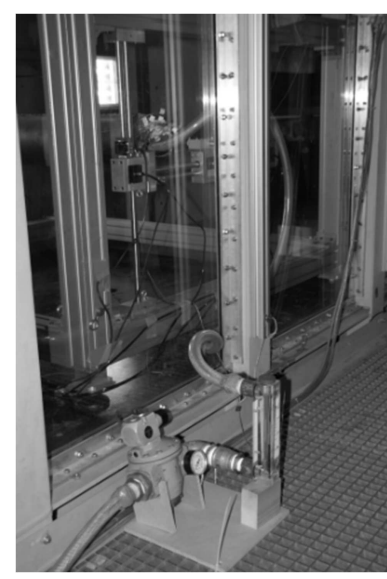

Figure 6 Compressed air pipe entry into the test section 


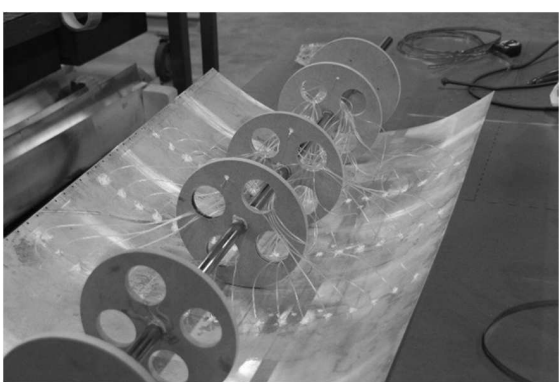

Figure 7 Internal structure of the model

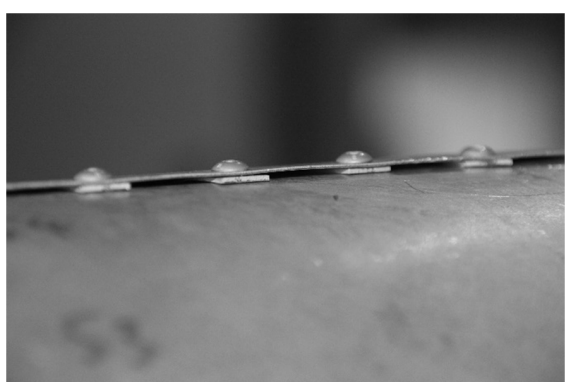

Figure 8 Slot along the cylinder

model. The single 1-millimeter-high slot runs along the entire length of the cylinder. The model is made up of an aluminum skin glued onto six wooden circular sections with a width of $0.015 \mathrm{~m}$. A supporting steel bar, with a diameter of $0.02 \mathrm{~m}$ and a length of $1.8 \mathrm{~m}$, passes through the six circular sections (Fig. 7). In order to maintain the slot's height along the cylinder, 44 aluminum spacers ( $0.01 \mathrm{~m}$ wide and $1 \mathrm{~mm}$ high) are riveted in between the aluminum skin overlaps. Consequently, the true size of the slot is $0.66 \times 0.001 \mathrm{~m}$ (length $\times$ height) (Fig. 8).

Inside the aeronautic test section, the model was installed on an instrumented support structure, which allowed the measurement of lift and drag. The steel bar extremities were attached to the structure with clamping screws, allowing easy rotation of the cylinder around its longitudinal axis (Fig. 9). The lift and drag were measured by six load cells connected to a National Instruments data acquisition module.

The pressure distribution was measured at three transversal sections located at $0.35,0.55$, and $0.75 \mathrm{~m}$ from the cylinder's extremity. Around each of these three sections, 18 pressure tappings were symmetrically positioned (see Fig. 7). They were linked to a 64-channel PSI pressure scanner, which measured the pressures with a sampling frequency of $100 \mathrm{~Hz}$. The pressure data acquisition was carried out by means of a CANdaq module.

The air blowing out through the slot was injected into the cylinder at one of its extremities. The incoming volumetric flow and pressure were adjusted and measured using a pressure regulator and a rotameter. These instruments were located just before the entry of the compressed air pipe into the aeronautic test section (see Fig. 6).

The tested wind tunnel speeds were 8 and $13 \mathrm{~m} / \mathrm{s}$, while the jet mass flows per unit span were $0.0536,0.0745$, and $0 \mathrm{~kg} /(\mathrm{m} \cdot \mathrm{s})$. Using an atmospheric pressure ratio of $101325 \mathrm{~Pa}$, these mass flow rates equate to pressure ratios of 1.055 , 1.027 , and 0 , respectively.

The original intention was to test 8 and $15 \mathrm{~m} / \mathrm{s}$, in order to be consistent with the computational study. However, it was found that $15 \mathrm{~m} / \mathrm{s}$ resulted 

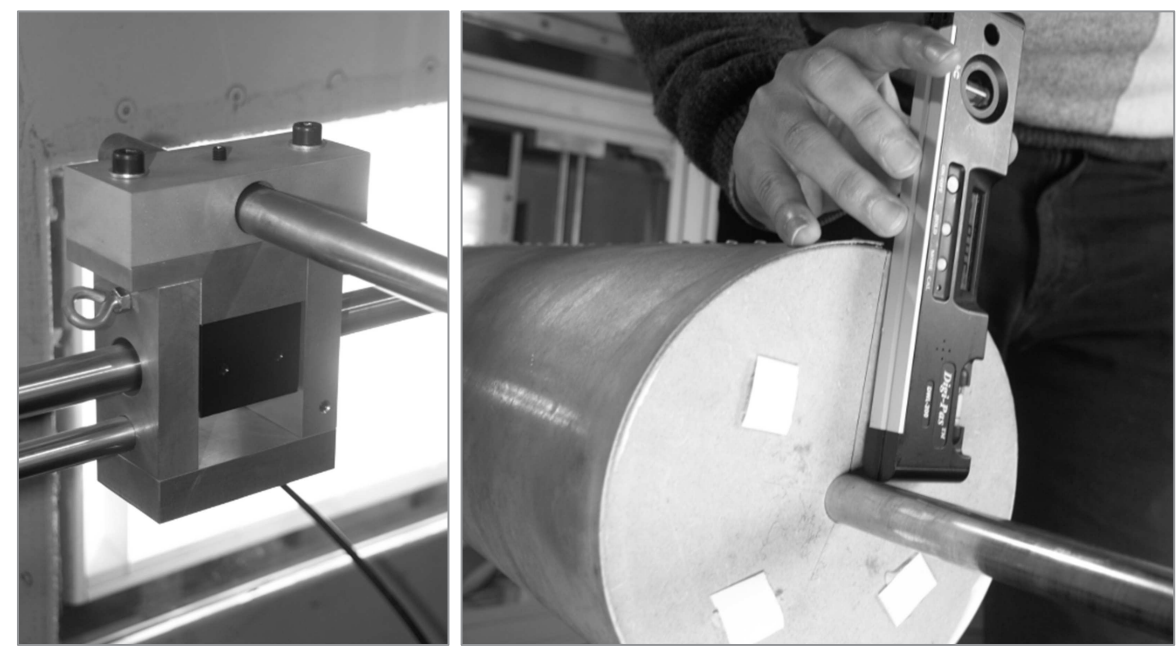

Figure 9 Slot angle position modification
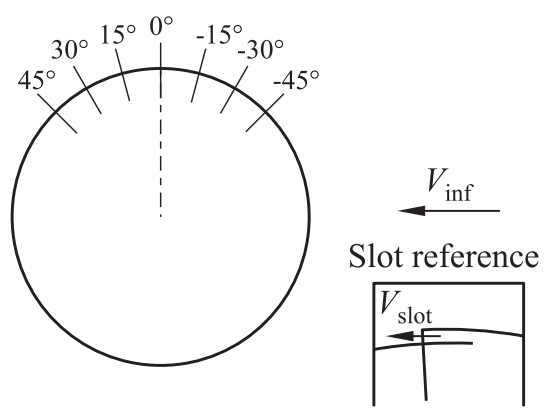

Figure 10 Slot angle positions in a strong vibration of the apparatus. For safety reasons, the wind tunnel speed had to be decreased until these vibrations ceased.

Thus, six combinations of wind speed and mass flow rate were investigated and for each one, seven slot angle positions were tested. Pressure and force measurements were recorded for all the tested configurations. The seven slot angle positions can be seen in Fig. 10.

\subsection{Computational Method}

The problem was studied in two dimensions, using the NUMECA computational fluid dynamics (CFD) suite FINE/Open. The mesh was designed, over a series of iterations to be common for all of the test cases, which included vertical downwash (hover and vertical climb), horizontal flow (sideward flight), and vertical upward flow (descent). The mesh was unstructured and created using NUMECA's HEXPRESS tool. 


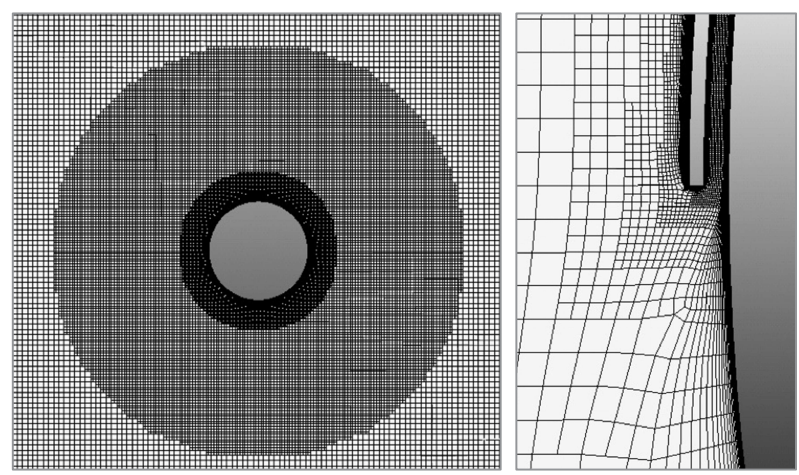

Figure 11 HEXPRESS mesh design for computational studies in FINE/Open

The model selected necessitated the efficient use of cells and rapid expansions from the very small dimension of the 1-millimeter slot out to the large dimension of the 0.2 -meter diameter boom, to a far field measuring $7 \times 7$ diameters. The far-field distance and near-field resolution were chosen after a number of iterations and with particular attention to the $y^{+}$value at the boom surface and the contribution of the far-field flow phenomena to the overall forces on the tail boom. The $y^{+}$value at the boom surface was kept less than 1.0 in all areas, for all cases. This represented a particular challenge for the cases at higher pressure ratios (intended for regimes of flight where a greater yawing moment is needed), because the higher pressure ratio naturally results in a greater ejection speed from the slot. Ultimately, the first layer thickness was chosen to be $5 \mu \mathrm{m}$. Using a number of expansion areas out to a maximum cell width of $0.04 \mathrm{~m}$ (roughly $10 \%$ of boom diameter), this resulted in a mesh with a fairly economical 76,200 cells. The mesh is depicted in Fig. 11. In the interest of adequately depicting the mesh in high-resolution areas, the full domain is not depicted here.

The SST $(k-\omega)$ turbulence model was chosen due to its sensitivity to flow separation point and accurate prediction of aeronautics flows with strong adverse pressure gradients. This is a 2-equation eddy-viscosity model [9] and is wellsuited to the problem at hand. It was anticipated from the outset that the separation point would play a critical role in determining the circulation and the resulting forces on the cylinder.

Early on, two important observations were made with regards to the attached flow. First, the flow was highly unsteady in many of the cases originally selected, including a "default" case meant to represent the start of a yawing motion departing from hover, with vertical downwash and an ejection pressure ratio as low as 1.15. Second, when looking at the intended range of pressure ratios (1.051.50 ), it was found that several test cases produced a vertical force on the cylinder of the same order of magnitude as the horizontal force. In other words, there 
would be a substantial and quite undesirable cross coupling between yaw and pitch forces. These preliminary findings are documented further in section 3 , but the findings were sufficient to rethink the scope of the numerical study, because it was clear already that the examined directional control design would not be suitable for implementation in a helicopter without some modification.

On the basis of these early findings, the computational work was refined in scope, and became more of a theoretical investigation of the Coandă flow separation point. It was decided to examine two freestream velocities: 8 and $15 \mathrm{~m} / \mathrm{s}$. Five pressure ratios were selected: $1.05,1.15,1.25,1.35$, and 1.45. Four downwash angles $(\alpha)$ were examined: $0^{\circ}, 90^{\circ}, 180^{\circ}$, and $270^{\circ}$ (refer to Fig. 3 for angle notation). This produces a total of 40 cases that were simulated. Each was solved using the unsteady solver, as it was not known a priori which cases would produce an unsteady result. The initial solution used 10,000 iterations to allow the flow to fully develop. A minimum of 100 time steps of $0.01 \mathrm{~s}$ were then computed in order to assess whether the problem was unsteady. If the result was found to be unsteady, 300-700 additional time steps were computed as necessary to capture at least one full oscillation of the unsteady response, as observed in the lift or drag coefficients in the FINE/Open monitor.

\section{EXPERIMENTAL RESULTS}

Drag and lift coefficients were obtained from the pressure measurements by integrating the pressure coefficients over the central circular section. The drag coefficient $C_{d}$ obtained in this way did not take the friction drag into account. These lift and drag coefficients were compared to the ones obtained from the load cell measurements. The free-stream Reynolds numbers of $1.06 \cdot 10^{5}$ and $1.72 \cdot 10^{5}$ correspond, respectively, to the tested wind tunnel speeds 8 and $13 \mathrm{~m} / \mathrm{s}$.

Figure $12 a$ shows the results obtained without jet blowing. At Reynolds numbers of the order of $10^{5}$, classical cylinder theory and experiments predict a laminar boundary layer separation at $-10^{\circ}$. For slot angle positions between $-45^{\circ}$ and $-15^{\circ}$, the slot seems to delay the boundary layer separation (due to forced turbulent transition) on the upper surface of the cylinder. Therefore, these three slot angle configurations appear to significantly increase the lift coefficient (from 0 to approximately 0.5 ) and to decrease the drag coefficient (from around 0.9 to around 0.7 ).

The results for the test configurations with the weak jet blowing case $(0.0536 \mathrm{~kg} /(\mathrm{s} \cdot \mathrm{m}))$ are shown in Fig. 12b. The effectiveness of the Coandă sheet was significantly affected by the slot angle position. In the higher free stream Reynolds case, the drag coefficient seems to be approximately constant at 0.5 while the lift coefficient increases from approximately 0.9 to around 1.1 for slot angle positions between $-45^{\circ}$ and $15^{\circ}$. For slot angle positions of $30^{\circ}$ and $45^{\circ}$, 

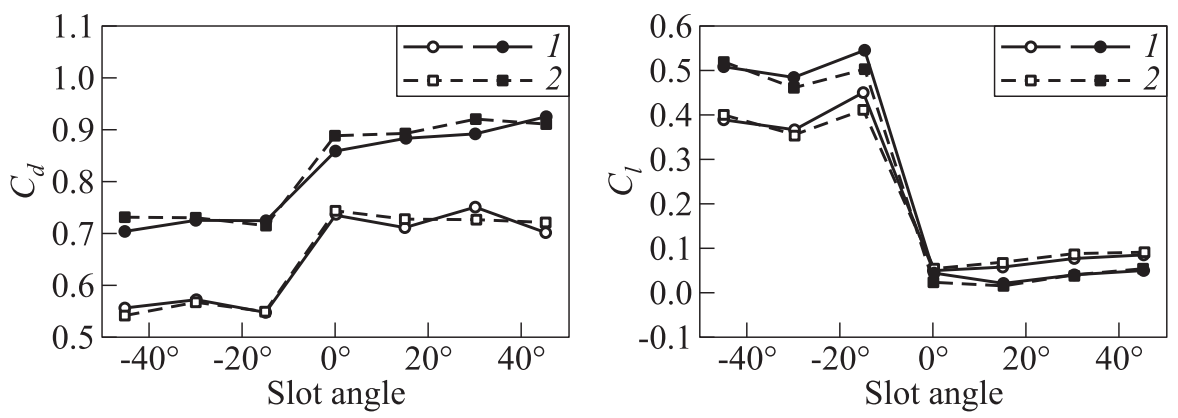

(a)
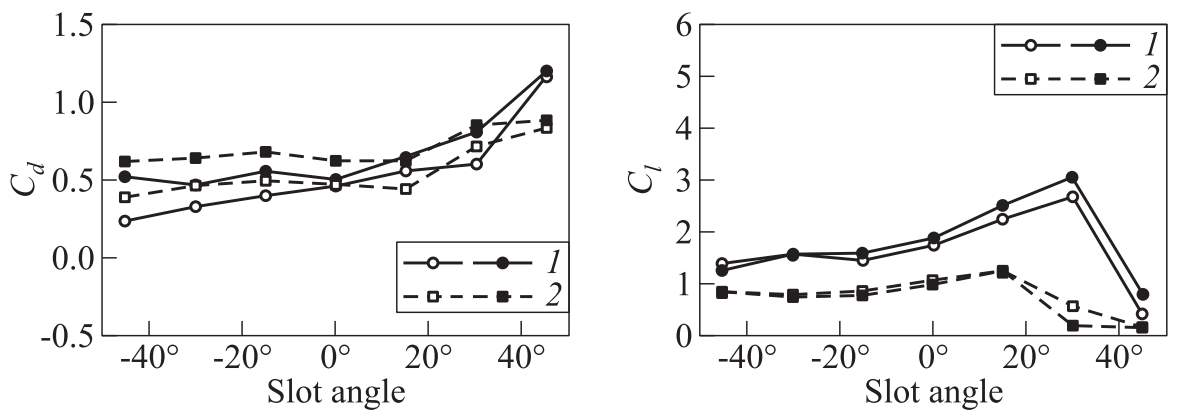

(b)
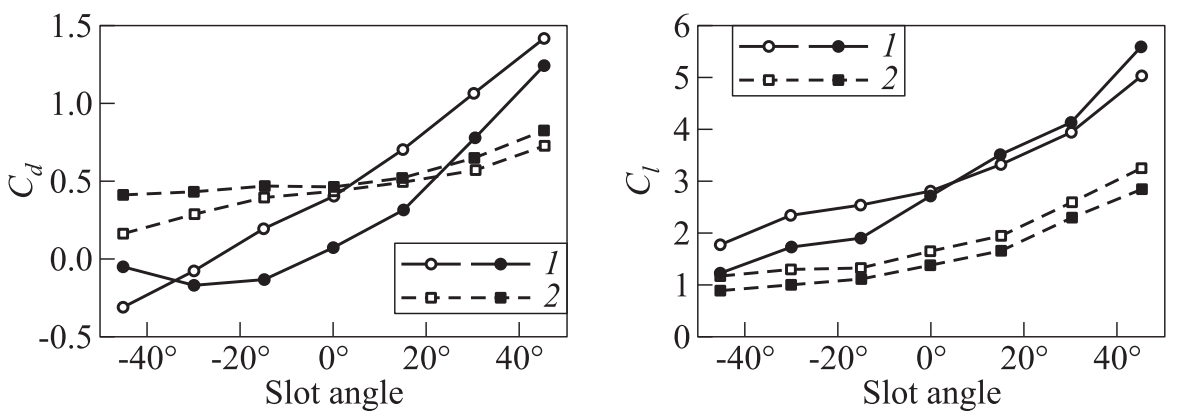

(c)

Figure 12 Drag (left column) and lift (right column) coefficients vs. slot angle position without jet blowing $(a)$, in the weak jet blowing case (drag (lift) coefficient - jet flow per unit span $=0.0536 \mathrm{~kg} /(\mathrm{s} \cdot \mathrm{m}))(b)$; and in the strong jet blowing case (drag (lift) coefficient - jet flow per unit span $=0.0745 \mathrm{~kg} /(\mathrm{s} \cdot \mathrm{m}))(c): 1-\mathrm{Re}_{1}=1.06 \cdot 10^{5} ; 2-$ $\mathrm{Re}_{2}=1.72 \cdot 10^{5}$; empty signs refer to integrated pressures; and filled signs refer to measured forces 
the efficiency of the Coandă sheet significantly decreased, resulting in a lift coefficient decrease to approximately 0.1 and a drag coefficient increase to approximately 0.7. In the lower free stream Reynolds case, the Coandă sheet remained efficient for the six first slot angle positions and it produced higher lift coefficient values reaching approximately 3 for the 30 degree slot angle position.

Figure $12 c$ shows the results for the test configurations in the strong jet blowing case $(0.0745 \mathrm{~kg} /(\mathrm{s} \cdot \mathrm{m}))$. The Coandă sheet remained effective in all test configurations. In the higher free stream Reynolds case, the drag coefficient increased from approximately 0.25 to 0.65 and the lift coefficient increased approximately from 1 to 2.7 with increasing slot angle position. In the lower free-stream Reynolds case, the drag coefficient increased approximately from -0.2 to 1.2 and the lift coefficient increased approximately from 1.5 to 5 .

\section{COMPUTATIONAL RESULTS}

The numerical results of the computational study are shown in Fig. 13. One of the most important things to note in these results is that the lift coefficient is of the same order of magnitude as the drag coefficient (see Fig. 13). In many phases of flight, this means that the pilot's pedal inputs, in addition to the desired side force on the cylinder and resulting yawing moment, would also result in a substantial vertical force on the cylinder. For the most typical flight conditions, with vertical downwards downwash over the cylinder, there will be a strong downward-pitching moment on the fuselage resulting from this phenomenon. The forces are detailed in Table 1. Refer to Fig. 3 for the axis system by which $\alpha$ is measured.

It must also be noted that many of the cases had unsteady final states. This was common in the cases where the stagnation point was no longer located on the cylinder due to the combination of ejection pressure ratio and downwash angle and velocity. The motility of the stagnation point is explained in Figs. 14 and 15.

Unfortunately, the quantitative results from the computational study do not compare well to the quantitative results from the experimental study. The forces calculated using FINE/Open are simply too large in magnitude to be taken seriously in comparison to the forces observed in the wind tunnel. These unrealistically large force values result in unrealistically large coefficients of lift and drag. Most likely, this issue is arising from some kind of user error with FINE/Open. It is possible that the incorrect faces are selected to integrate pressures to generate the forces. For a future study, more time should be set aside to compare the quantitative data early on in the experimental process, so that fine-tuning can be done to eliminate any existing errors that can contribute to these inconsistencies between the quantitative results from the two sources. 


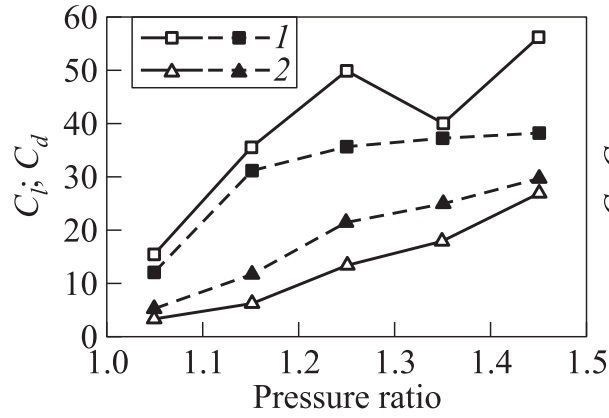

(a)

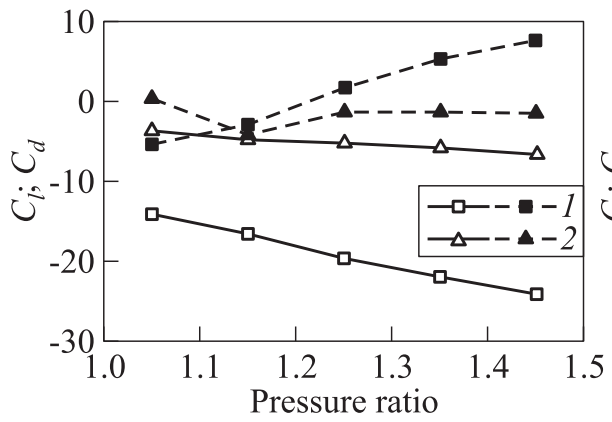

(c)

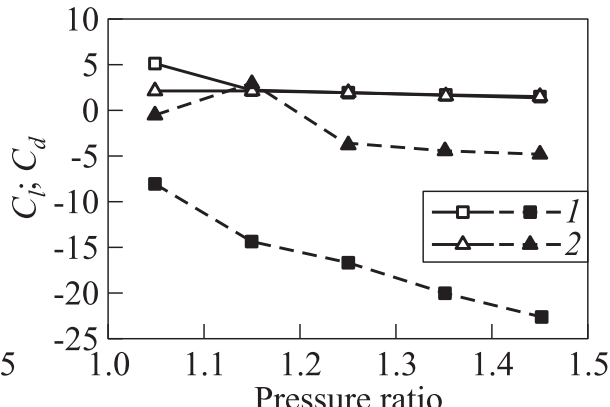

(b)

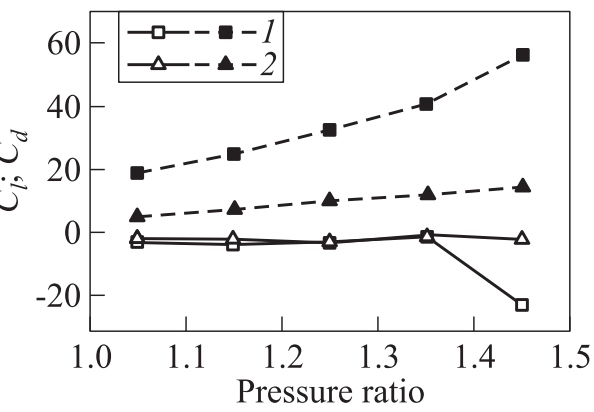

(d)

Figure 13 Lift (filled symbols) and drag (empty symbols) coefficients per unit length; computational results at flow angle $0^{\circ}(a) ; 90^{\circ}(b) ; 180^{\circ}(c)$; and $270^{\circ}(d): 1-8 \mathrm{~m} / \mathrm{s}$; and $2-15 \mathrm{~m} / \mathrm{s}$

Table 1 Summary of forces based on computational data

\begin{tabular}{|c|c|c|c|c|c|c|c|c|c|}
\hline \multirow{2}{*}{$\begin{array}{c}\text { Tunnel } \\
\text { speed, } \\
\mathrm{m} / \mathrm{s}\end{array}$} & \multirow[b]{2}{*}{$\begin{array}{c}\text { Pressure } \\
\text { ratio }\end{array}$} & \multicolumn{2}{|c|}{$0^{\circ}$} & \multicolumn{2}{|c|}{$90^{\circ}$} & \multicolumn{2}{|c|}{$180^{\circ}$} & \multicolumn{2}{|c|}{$270^{\circ}$} \\
\hline & & $\begin{array}{c}F_{x}, \\
\mathrm{~N} / \mathrm{m}\end{array}$ & $\begin{array}{c}F_{y}, \\
\mathrm{~N} / \mathrm{m}\end{array}$ & $\begin{array}{c}F_{x}, \\
\mathrm{~N} / \mathrm{m}\end{array}$ & $\begin{array}{c}F_{y}, \\
\mathrm{~N} / \mathrm{m}\end{array}$ & $\begin{array}{c}F_{x}, \\
\mathrm{~N} / \mathrm{m}\end{array}$ & $\begin{array}{c}F_{y}, \\
\mathrm{~N} / \mathrm{m}\end{array}$ & $\begin{array}{c}F_{x}, \\
\mathrm{~N} / \mathrm{m}\end{array}$ & $\begin{array}{c}F_{y}, \\
\mathrm{~N} / \mathrm{m}\end{array}$ \\
\hline \multirow{5}{*}{8} & 1.1 & 91.4 & -117.6 & 38.6 & -63.5 & 40.2 & -108.1 & 16.3 & -147.7 \\
\hline & 1.2 & 241.6 & -274.5 & 17.1 & -112.1 & 22.7 & -128.2 & 21.5 & -196.6 \\
\hline & 1.3 & 276.6 & -386.3 & 14.0 & -128.6 & -12.1 & -150.6 & 18.5 & -252.6 \\
\hline & 1.4 & 289.3 & -309.8 & 11.7 & -153.6 & -41.0 & -168.0 & 1.4 & -314.3 \\
\hline & 1.5 & 296.1 & -432.8 & 10.0 & -175.0 & -57.6 & -184.9 & 170.7 & -436.0 \\
\hline \multirow{5}{*}{15} & 1.1 & 139.9 & -116.6 & 55.2 & -13.4 & -13.5 & -95.8 & 15.2 & -156.8 \\
\hline & 1.2 & 330.4 & -179.5 & 58.3 & 77.9 & 103.7 & -123.1 & 21.0 & -240.7 \\
\hline & 1.3 & 595.2 & -379.8 & 48.4 & -101.6 & 32.7 & -137.8 & 25.4 & -304.1 \\
\hline & 1.4 & 691.3 & -500.7 & 41.9 & -114.9 & 38.3 & -157.8 & 28.8 & -359.3 \\
\hline & 1.5 & 821.6 & -744.3 & 35.5 & -130.8 & 36.9 & -177.7 & 28.0 & -420.0 \\
\hline
\end{tabular}




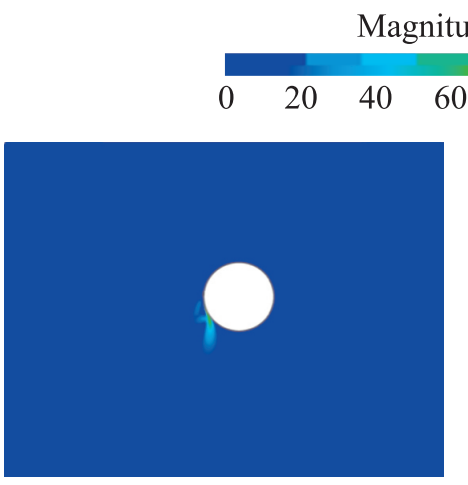

(a)

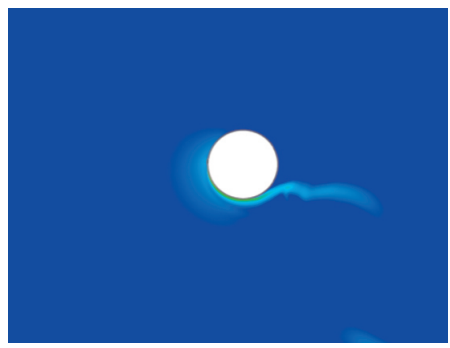

(c)

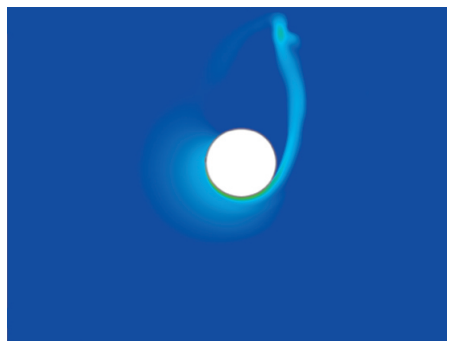

(e)

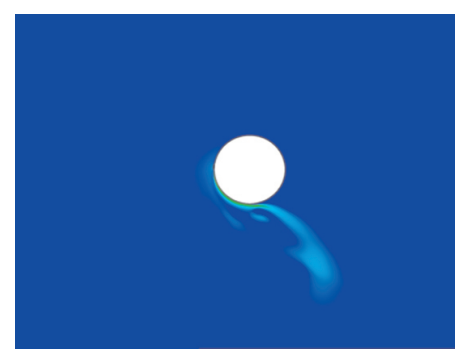

(b)

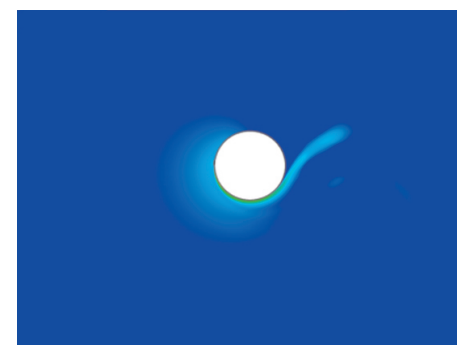

$(d)$

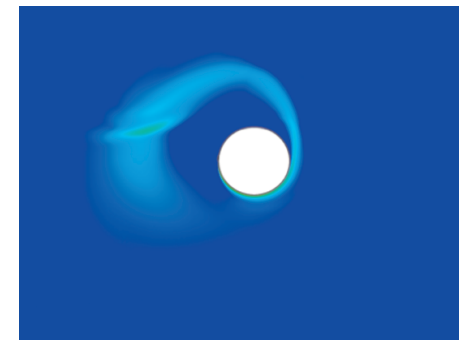

$(f)$

Figure 14 Developing flow $\left(0^{\circ}\right.$ downwash, $8 \mathrm{~m} / \mathrm{s}$ with $\left.\mathrm{PR}=1.35\right):(a) t=0.1 \mathrm{~s}$; (b) $0.3 ;(c) 0.5 ;(d) 0.7 ;(e) 0.9$; and $(f) t=1.1 \mathrm{~s}$

Ultimately, while the wind tunnel produces meaningful quantitative results, the computational study must be valued more for its qualitative results and the trends observed in the numerical data, which are largely consistent with the trends in the experimental results.

Putting aside the quantitative results, the computational study resulted in several interesting qualitative findings. First, it has been shown that, in certain conditions, the ejected flow from the slot will adhere to the cylinder and wrap 


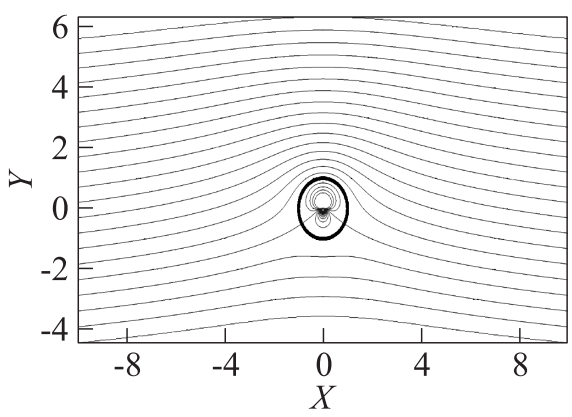

(a)

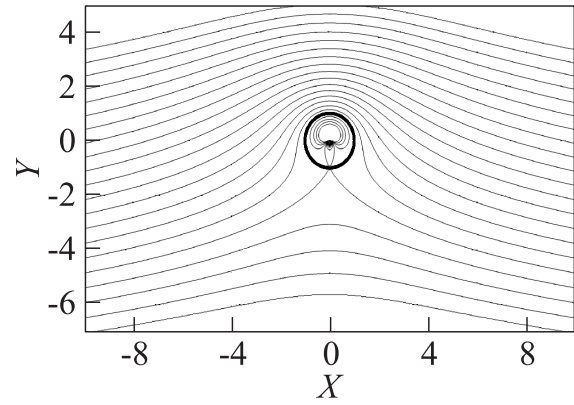

(b)

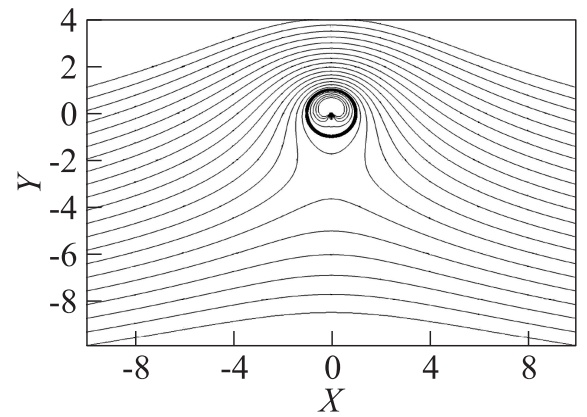

(c)

Figure 15 Motility of the stagnation points: $(a)$ two stagnation points on the cylinder (vortex $\left.=1, \Gamma /\left(4 \pi d v_{\infty}\right)<1\right) ;(b)$ one stagnation point on the cylinder $\left(\Gamma /\left(4 \pi d v_{\infty}\right)\right.$ $=1)$; and $(c)$ stagnation point is off the cylinder $\left(\Gamma /\left(4 \pi d v_{\infty}\right)>1\right)$

all the way around the tail boom. This occurs, especially in the case of higher ejection pressure ratios, because the stagnation point is no longer on the cylinder. Typically, in these cases, the stagnation point is found upstream of the cylinder, on the side opposite the active slot. This finding is interesting because it reflects the fact that the stagnation point moves as the flow develops, and in unsteady cases, continues to move after the flow is fully developed. A series of time-steps exhibiting the flow development around the cylinder are shown in Fig. 14.

It can be shown that the nondimensional circulation $\Gamma /\left(4 \pi d v_{\infty}\right)$ influences the position of the stagnation points in the flow on the cylinder. Using complex potential theory, it is found that there are two stagnation points on a cylinder, which move towards each other as $\Gamma /\left(4 \pi d v_{\infty}\right)$ increases, up to a point where they merge. Increasing $\Gamma /\left(4 \pi d v_{\infty}\right)$ any further will cause the stagnation point to separate and move away from the cylinder (see Fig. 15). Even though this behavior is typical for inviscid flows, the present simulations demonstrate a similar breakaway stagnation point to exist viscous flows with slot blowing. When the stagnation point is no longer attached to the cylinder surface, the slot will blow 


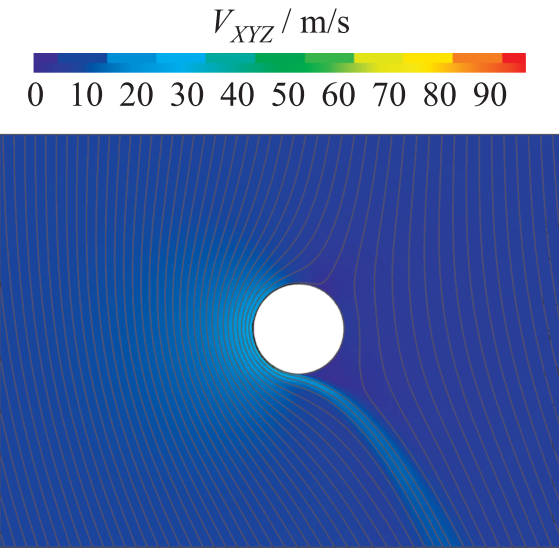

(a)

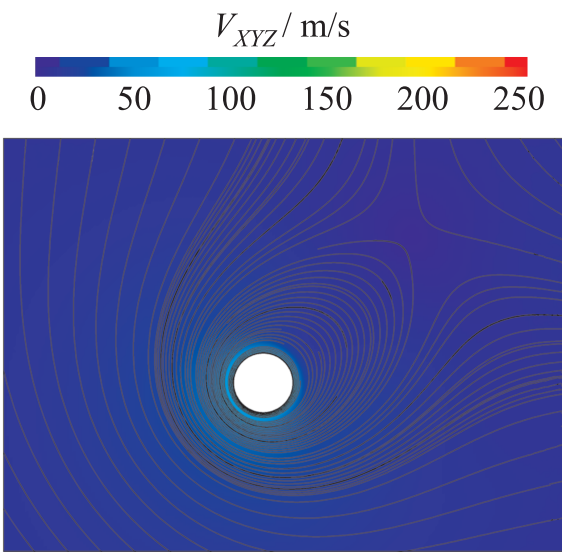

(b)

Figure 16 Vertical downwash (0 degree flow) case at $8 \mathrm{~m} / \mathrm{s}:(a) 1.05$ pressure rate, stagnation points on cylinder; and $(b) 1.45$ pressure rate, stagnation points off cylinder

air inside the volume delimited by the stagnation streamline, which will likely result in an unsteady flow field and, thus, is potentially dangerous when used for helicopter yaw control. The existence of this phenomenon should, therefore, be examined.

For most angles of attack, the simulations show that there are two stagnation points on the cylinder at the lowest pressure ratio studied computationally: 1.05. When the pressure ratio is increased, the stagnation point moves off the cylinder, which is consistent with the increased circulation that is exhibited due to higher ejection velocities resulting from the higher ejection pressure ratio. An example is shown in Figs. $16 a$ and 16b, which come from the vertical downwash (0 degree flow) case at $8 \mathrm{~m} / \mathrm{s}$, with ejection pressure ratios equal to 1.05 and 1.45 , respectively.

Another interesting qualitative and quantitative finding was the unsteady nature of the flow in some cases. This could not consistently be predicted by angle of attack or ejection pressure ratio, and the vortex shedding phenomenon is interesting to observe because of the relatively high speeds involved due to the insertion of the jet flow. This shedding phenomenon is shown in Fig. 17. The graphics come from the $8 \mathrm{~m} / \mathrm{s}, 90$ degree flow angle case (horizontal flow from the right), with a pressure ratio of 1.05 .

The frequency and amplitude of the oscillations in the forces (and nondimensional vorticity) about the cylinder varied from one case to the next. These figures show a case of comparatively high amplitude variation in the flow field from one time step to the next, occurring at a surprisingly low frequency of 


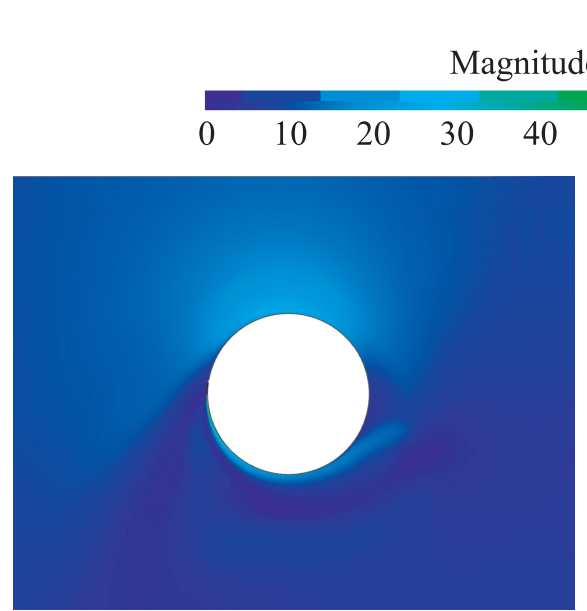

(a)

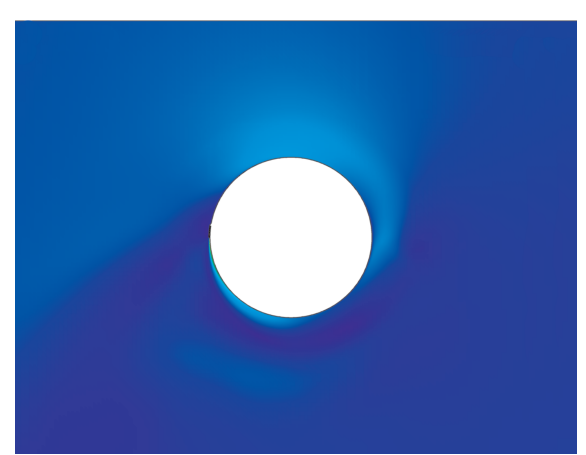

(b)

Figure 17 Downwash at $90^{\circ}, 8 \mathrm{~m} / \mathrm{s}$, pressure ratio $=1.05:(a) t=0 \mathrm{~s}$; and $(b) t$ $=1.5 \mathrm{~s}$

roughly $0.5 \mathrm{~Hz}$. This type of flow field behavior could be highly problematic from a standpoint of helicopter handling qualities and passenger comfort.

\section{CONCLUDING REMARKS}

It has been shown here that the proposed tail boom design is a promising concept for directional control in the application of the REDT helicopter. However, a number of problems have been identified by both the experimental and the computational investigations. Resonance phenomena in certain flight conditions limited the maximum air speed at which wind tunnel experiments could be carried out. The anticipated pitch-yaw coupling peculiar to the studied configuration will be an equally significant obstacle to overcome if intended for use on a helicopter. The existence of a sizeable vertical force associated with the desired side force on the cylinder was observed in both components of the study. The designers should seek to develop flow control devices that can help to eliminate the vertical component of the ejected flow. Future academic efforts to investigate this design should aim to achieve better overlap between the cases examined with computational and experimental results as a means to produce more robust quantitative findings. Finally, a complete numerical and experimental investigation of this design should attempt to better simulate the complex and highly nuanced three-dimensional downwash flow field of a helicopter rotor. 


\section{ACKNOWLEDGMENTS}

The authors would like to thank Dr. Simon Newman for contributing his MATLAB code which was useful in determining the stagnation point for flow past a cylinder.

\section{REFERENCES}

1. Buysschaert, F., P. Hendrick, and S. Newman. 2011. Conventional helicopters: An adaptiveness study for more electric and alternative propulsion technologies. J. Aerospace Eng. 226:1078-1094.

2. Nelms, D. July 9, 2012. Speed streak. Aviation Week Space Technology. 64-66.

3. Houghton, E. L., and P. W. Carpenter. 2003. Boundary layer control for the prevention of separation. Aerodynamics for engineering students. Oxford: ButterworthHeinemann. 508-512.

4. Sobey, I. J. 2000. Introduction to interactive boundary layer theory. Oxford: Oxford UP. $284-285$.

5. Cîrciu, I., M. Boşcoianu, and H. Coanda. 2010. An analysis of the efficiency of Coanda - NOTAR anti-torque systems for small helicopters. Incas Bulletin 2.4. 81-88.

6. Liu, Y., L. Sankar, R. Englar, and K. Ahuja. 2001. Numerical simulations of the steady and unsteady aerodynamic characteristics of a circulation control wing airfoil. AIAA Paper No. 2001-0704.

7. Tongchitpakdee, C., S. Benjanirat, and L. Sankar. 2006. Numerical studies of the effects of active and passive circulation enhancement concepts on wind turbine performance. J. Solar Energy Eng. 128(4):432.

8. Antoine, H., G. Dimitriadis, P. Hendrick, E. Kagambage, and T. Rayee. 2009. A novel concept for helicopter rotor drives. 3rd European Conference for Aero-Space Sciences. Versailles, Paris, France.

9. Menter, F. R. 1994. Two-equation eddy-viscosity turbulence models for engineering applications. AIAA J. 32(8):269-289. 